\title{
RECICLAGEM DE ÓLEO COMESTÍVEL E FABRICAÇÃO DE SABÃO COMO INSTRUMENTOS DE EDUCAÇÃO AMBIENTAL
}

\author{
Loreni Beatriz Arnold Wildner, Clayton Hillig
}

\section{RESUMO}

Este estudo tem como principal objetivo investigar o nível de compreensão de 32 profissionais que trabalham na Escola Municipal Infantil Solange Ana Copetti, integrante da rede municipal de ensino de ljuí, sobre a poluição provocada pelo descarte inadequado do resíduo de óleo comestível. Constatou-se que o consumo mensal varia, sendo que $44 \%$ do grupo consomem de 2 a 3 litros e 13\% consomem 3 a 4 litros, sendo que destes consumidores $41 \%$ descarta uma quantidade relativamente alta, mais de um litro por mês. As formas de descarte são variáveis, sendo que $9 \%$ colocam diretamente na pia, $12 \%$ dispõe no solo, $25 \%$ faz doação e $41 \%$ guarda para fazer sabão, $4 \%$ coloca no lixo comum e $9 \%$ reutiliza para fazer comida para animais ou fazer fogo na churrasqueira. Adicionalmente buscou-se conscientizar o grupo sobre as principais conseqüências do descarte inadequado (impermeabilização do solo, contaminação da água e produção de gás metano, responsavel pelo efeito estufa), através de palestra de conscientização e oficina de fabricação de sabão. Também se buscou formar multiplicadores ambientais, visando difundir informações ambientais e promover o engajamento na luta por um meio ambiente equilibrado e saudável.

Palavras-chave: Reciclagem, Óleo comestível, Sabão.

\section{ABSTRACT}

This study has as main objective to investigate the level of understanding of 32 professionals who work at the Municipal School Children Copetti Solange Ana, a member of the municipal school of Ijuí on pollution caused by improper disposal of waste edible oil. It was found that the monthly consumption varies, and consumes $44 \%$ of group 2 to 3 liter and 13\% consume 3 to 4 liters, and $41 \%$ of these consumers discard a relatively large amount, more than one liter per month. The modes of disposal are variable, and $9 \%$ put directly into the sink, the soil has $12 \%, 25 \%$ and donates $41 \%$ saved for soap, put in $4 \%$ and $9 \%$ trash reused to make food for animals or make fire in grill. Additionally we sought to educate the group about the main consequences of improper disposal, (soil sealing, water contamination and methane gas production, responsible for the greenhouse effect), through awareness lecture and workshop manufacture of soap. Also sought be formed environmental multipliers, aiming to disseminate environmental information and promote engagement in the struggle for a healthy and balanced environment.

Keywords: Recycling, Edible Oil, Soap. 


\section{Revista Eletrônica em Gestão, Educação e Tecnologia Ambiental}

REGET/UFSM (e-ISSN: 2236-1170).

\section{INTRODUÇÃO}

O ser humano ao longo da história sempre utilizou o Meio Ambiente para sanar suas necessidades, por muito tempo manteve com ele uma relação equilibrada, pois retirava dele somente o que realmente necessitava para a sua sobrevivência. Mas com o passar dos tempos ocorreram mudanças na forma de vida das pessoas, o homem fixou-se a terra, surgiram novas tecnologia e necessidades que refletiram diretamente no modo de vida das pessoas e na forma de utilização e exploração dos recursos naturais. Além de explorá-los indiscriminadamente e reduzir significativamente as reservas de água potável, ar puro e solo produtivo, atualmente, a humanidade descarta seus dejetos aumentando assustadoramente a produção de lixo em todo o planeta.

O lixo é o maior causador da degradação do meio ambiente e pesquisas indicam que cada ser humano produz, em média, pouco mais que 1 quilo de lixo por dia. Isto acarretou em sérios problemas relacionados ao meio ambiente que estão bem visíveis na sociedade, seja por meio das alterações na paisagem ou no clima que nos cerca, seja por meio da mídia que diariamente nos bombeia com relatos de desastre e catástrofes locais e mundiais.

Com isso percebe-se claramente, que o meio ambiente já bastante degradado pelo desenvolvimento social e industrial clama por atos que busquem a sua preservação. Procurando aliviar o impacto ecológico criado pela expansão do consumo, bem como se desenvolver como atividades econômicas surgem os canais reversos. São atividades que procuram reduzir a utilização de matérias-primas virgens através do reaproveitamento e reprocessamento de materiais obtidos a partir da pós-venda.

Resíduos como o vidro, plástico, papel e alumínio podem ser retornados à linha de produção quando segregados na fonte e repassados a entidades beneficiadoras. Tais resíduos, ao retornarem à linha de produção, geram empregos a quem realiza a coleta, agrega valor ao material antes descartado e contribui para a preservação ambiental, considerando a economia de insumo na produção de outro bem.

Outro produto muito utilizado atualmente na produção e consumo de alimentos fritos e pré-fritos e que resulta em grande produção de resíduos é o óleo comestível residual ou óleo e gordura residual-ORG, que quando descartado inadequadamente gera graves danos ao meio ambiente, mas que também já começa a ser reconhecido como resíduo potencialmente reciclável, podendo servir como matéria-prima na fabricação de diversos produtos, tais como biodiesel, tintas, óleos para engrenagens, sabão, detergentes, entre outros.

Mas apesar de ser uma alternativa bastante viável, a reciclagem do óleo comestível ainda é desconhecida da maioria da população e até dos grupos funcionais das escolas incluindo também, os educadores.

Com objetivo de conscientizar as pessoas (profissionais que trabalham na escola) que o descarte inadequado do óleo comestível pode trazer graves danos ao meio ambiente; despertar para a importância de incluir ciclo reverso do produto pode trazer vantagens competitivas e evitar a degradação ambiental e problemas no sistema de tratamento de água e esgotos; e formar multiplicadores ambientais visando difundir informações ambientais e promover o engajamento na luta por um meio ambiente equilibrado e saudável, foi promovido diversas atividades, como, entrevistas, palestra de conscientização e oficina de fabricação de sabão.

Dessa forma buscou-se divulgar a idéia de que a reciclagem por si só não pode ser considerada a solução, mas que a mudança de hábitos e atitudes pode levar a sociedade a tomar medidas mais abrangentes, com ações que minimizem a quantidade de resíduos na própria fonte 
geradora, reciclando e reutilizando o óleo os excedentes, esperando contribuir pela melhoria no manejo e destino menos poluente deste resíduo.

\section{METODOLOGIA}

Para o presente estudo, a metodologia utilizada buscou responder às seguintes questões norteadoras: Quais os problemas que podem ser evitados com descartes adequados para o óleo comestível? Quais são os tipos de descartes para os resíduos de óleo comestível que podem ser adotados sem causar poluição no meio ambiente? Existem métodos de reaproveitamento e, ou de reciclagem que podem ser adotados por qualquer pessoa na sociedade?

No que se refere ao método utilizado, pode-se dizer que a pesquisa utilizou-se do método quanti-qualitativo que pressupõe uma abordagem descritiva do problema em questão. Este procedimento explora particularmente a observação, análise documental, entrevistas semiestruturadas e diálogos informais com o grupo funcional da Escola (alvo da pesquisa) para chegar aos resultados esperados.

O presente trabalho estruturou-se em dois momentos. Inicialmente foi apresentada a intenção da pesquisa e aplicado o primeiro questionário. De posse destas informações foi agendada uma palestra com Rosemeri Martins de Oliveira coordenadora de desenvolvimento sócio ambiental da secretaria do meio ambiente do município de ljuí sobre poluição e contaminação do meio ambiente provocada pelo descarte inadequado do óleo usado. Em seguida foi desenvolvida a oficina de fabricação de sabão a partir do óleo comestível usado-ORG e aplicado o segundo questionário que embasou este trabalho.

Para finalizar, buscou-se analisar todo o material disponível para a pesquisa, bem como divulgar a idéia de que a reciclagem por si só não pode ser considerada a solução, mas que a mudança de hábitos e atitudes pode levar a sociedade a tomar medidas mais abrangentes, com ações que minimizem a quantidade de resíduos na própria fonte geradora, reciclando e reutilizando o óleo os excedentes, esperando contribuir pela melhoria no manejo e destino menos poluente deste resíduo.

\section{REVISÃO BIBLIOGRÁFICA}

\section{O Óleo Vegetal: Características Gerais}

O Brasil é um país que possui uma grande área agricultável, com grande diversidade climática e rica em espécies vegetais oleaginosas. Estas características lhe conferem um grande e variado potencial de extração de óleo e reflete na preparação de diferentes opções de alimentação e variados sabores.

Um dos derivados vegetais é o óleo que tem como matéria-prima as gorduras obtidas por meio de plantas e sementes como o caju, a linhaça, o girassol, o buriti, a mamona; grãos como o milho, a soja ou também por outros alimentos de origem vegetal tais como abacate, azeitona, abóbora, a canola, entre outros. Após o processo de refino e produção, o óleo obtido pode ser utilizado não só na preparação de alimentos, como também em componente de lubrificantes, itens de pintura ou como componente de combustível (COSTA NETO et al., 2000). 
Além disso, o Brasil é um dos maiores produtores mundiais de soja segundo dados da produção mundial 2006 - FAO/FAOSTAT ${ }^{1}$. Com a crescente produção de soja no Brasil, chegando, em 2001, a 37.218,40 mil toneladas, aumentou-se também o interesse de empregar as melhores tecnologias disponíveis na produção e colheita, influenciando diretamente na cotação internacional (CONAB, 2003 apud SAMPAIO, 2008).

Apesar de possuir um dos menores percentuais de conteúdo oleaginoso (se comparado com outras espécies oleaginosas) o óleo de soja apresenta também baixo custo na produção, fator que contribui para a redução do preço de revenda, e, por conseguinte, um aumento de popularidade e consumo, sendo usado largamente no processo de fritura, acompanhado, em menor escala, por outros tipos de óleos vegetais e gordura vegetal hidrogenada (COSTA NETO et al., 1999).

O óleo é um dos itens mais consumidos na refeição do brasileiro, pois segundo Nogueira e Beber (2009) além da utilização em frituras ele está intrinsecamente presente na composição de leguminosas, carnes e frutas e pode ser parte integrante na fabricação de pães e massas. Já a popularidade da soja na produção de óleo vegetal se deve ao fato de ser encontrada com maior facilidade no cenário brasileiro. Duas características presentes no óleo vegetal são importantes, tanto para o manuseio e consumo como também para o meio ambiente, que são a saturação e a insolubilidade em meio aquoso, respectivamente.

\section{Insolubilidade em Meio Aquoso, Locais de Descarte e Contaminação por Óleo Vegetal}

Os óleos são substâncias insolúveis em água (hidrofóbicas), pois são formados predominantemente por ésteres de triacilgliceróis (produtos resultantes da esterificação entre o glicerol e ácidos graxos), porém são solúveis em solventes orgânicos. Em função desta imiscibilidade e por possuir densidade menor que a água (ser mais leve), quando lançados em mananciais, emerge para a superfície, conforme Figura 1.

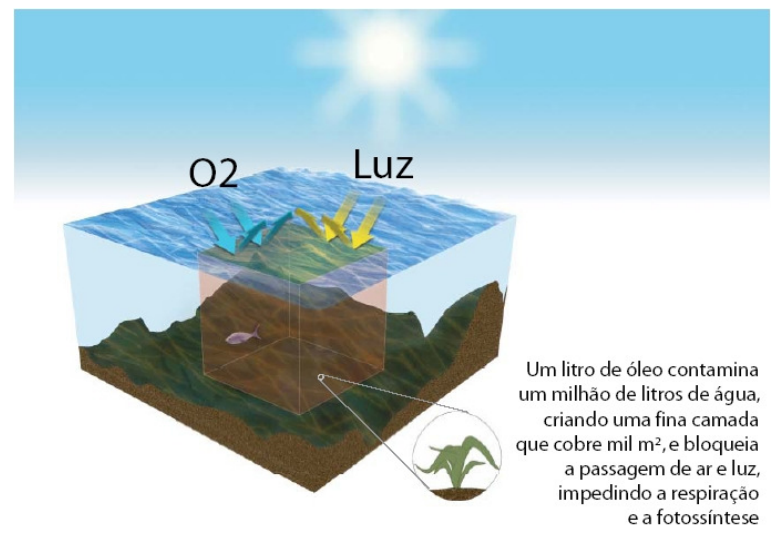

Figura 1 - Poluição provocada pelo óleo na água

Fonte: Refino: um enfoque ecológico. Disponível em: http://www.lubes.com.br/revista/ed02n04.html>.

Na superfície formam películas oleosas que além de diminuir e, ou acabar com a tensão superficial da água, segundo Sampaio (2003); Almeida (2002) dificultam a entrada de luz e oxigenação da água, comprometendo a base da cadeia alimentar aquática, os fitoplânctons e

\footnotetext{
${ }^{1}$ Food and Agriculture Organization of the United Nations.
} 
resultam conseqüentemente na mortandade de peixes e de todas as formas de vida no local afetado. Também contribui para a formação de bancos de lamas nos rios, contaminando, assim, águas que, por vezes, são usadas inadequadamente para o consumo humano.

De acordo com Alberici e Pontes (2004) e Almeida (2002), quando descartado na rede coletora de esgotamento sanitário, o óleo se acumula nas canalizações formando uma crosta, contribuindo para a sua obstrução. Para a retirada do óleo ou desentupimento das tubulações, que deve ser realizada periodicamente, são utilizados produtos químicos tóxicos como a soda cáustica. Tais medidas aumentam o custo do seu tratamento de esgoto em até $45 \%$ segundo Biodiselbr (2007), além de contribuir para a ocorrência de enchentes e proliferação de doenças, caso a desobstrução da tubulação não ocorra em tempo hábil.

De acordo com a American Public Helth Association² (APHA, 1992 apud NOGUEIRA; BEBER, 2009), a presença do óleo nas estações de tratamento prejudica o tratamento secundário biológico do esgoto, pois compromete os processos biológicos. Já segundo Esgoto Sanitário (1988 apud ALMEIDA, 2002), vale ressaltar que o tratamento dos esgotos sanitários ocorre em apenas $17 \%$ dos municípios brasileiros, além disso, ainda serve de alimento para baratas e roedores, aumentando suas populações e conseqüentemente a proliferação e transmissão de doenças. Isto sem mencionar os transtornos a população conseqüência dos buracos abertos na rua para fazer os desentupimentos das canalizações de esgoto obstruídas.

$\mathrm{Na}$ figura 2, é possível visualizar os danos em todas as etapas, do óleo residual que é descartado na rede de esgoto até chegar ao corpo receptor.

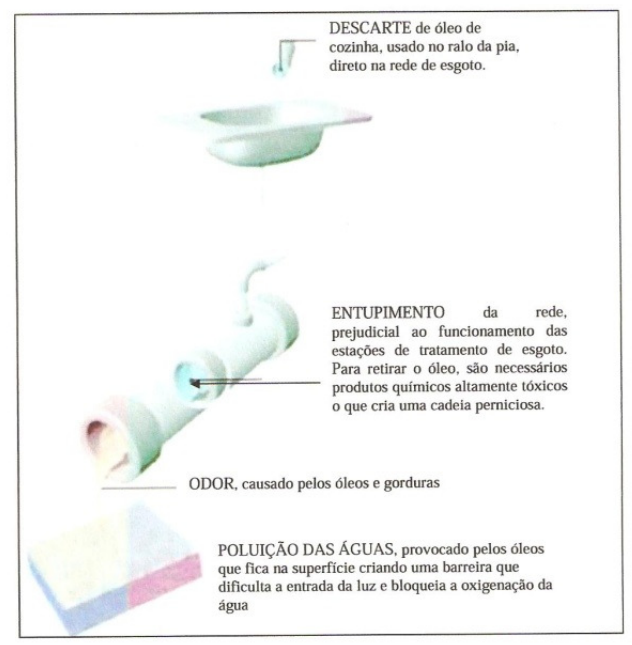

Figura 2 - Processo de saponificação da gordura na tubulação após seu lançamento na pia. Fonte: Rabelo e Ferreira (2008, p. 8 apud DIÁRIO DE NATAL, 2007).

Segundo o professor do Centro de Estudos Integrados sobre Meio Ambiente e Mudanças Climáticas da Universidade Federal do Rio de Janeiro - UFRJ, Alexandre D'Avignon, a decomposição do óleo de cozinha emite grandes quantidades de metano na atmosfera. Esse é um dos principais gases causadores do efeito estufa, que contribui para o aquecimento da terra.

\footnotetext{
${ }^{2}$ APHA, AWWA, EPA. Standard Methosds for the Examinationof Watter and Wastewater. 18th ed. AmericanPublicHealt Association, Washington D.C, 1992.
} 
Segundo ele, o óleo de cozinha que muitas vezes vai para o ralo da pia, acaba chegando ao oceano pelas redes de esgoto. Em contato com a água do mar, esse resíduo líquido passa por reações químicas que resultam em emissão de metano.

Quando lançado diretamente no solo, segundo Nogueira e Beber (2009) o óleo ocupa os espaços que naturalmente seriam ocupados pela água e pelo ar, ou seja, provoca a impermeabilização do solo. Como conseqüência a fauna e a flora deste local ficam impedidas de absorver os nutrientes e acabam morrendo, as sementes não conseguem germinar e o solo fica impróprio para o cultivo. A reparação deste solo, tornando-o fértil e apto a novos cultivos torna-se caro e difícil. Outro aspecto que precisa ser considerado é que ao ser lançado no solo o óleo entra em contato direto com a água que percola e escoa superficialmente e dependendo das características físicas químicas do solo e outras características como relevo e regime climático, pode migrar e atingindo mananciais hídricos e ate mesmo o lençol freático.

Outra forma de descarte adotado por muitas pessoas é colocar o óleo no lixo comum onde ira parar em aterros sanitários. Como o esquema típico de um aterro é a compactação do lixo, e se o aterro não possuir um sistema que impeça a infiltração do óleo nos taludes, como por exemplo, uma geomembrana de polietileno de alta densidade que promove a cobertura de uma área no solo impedindo o vazamento ou infiltração de efluentes, o óleo será descartado no lixo comum terá novamente como destino final as infiltrações e contaminação do lençol freático, além de diminuir a vida útil dos aterros sanitários.

Na figura 3 é possível visualizar a poluição provocada pelo óleo quando este é descartado na pia, no solo, ou no lixo comum.

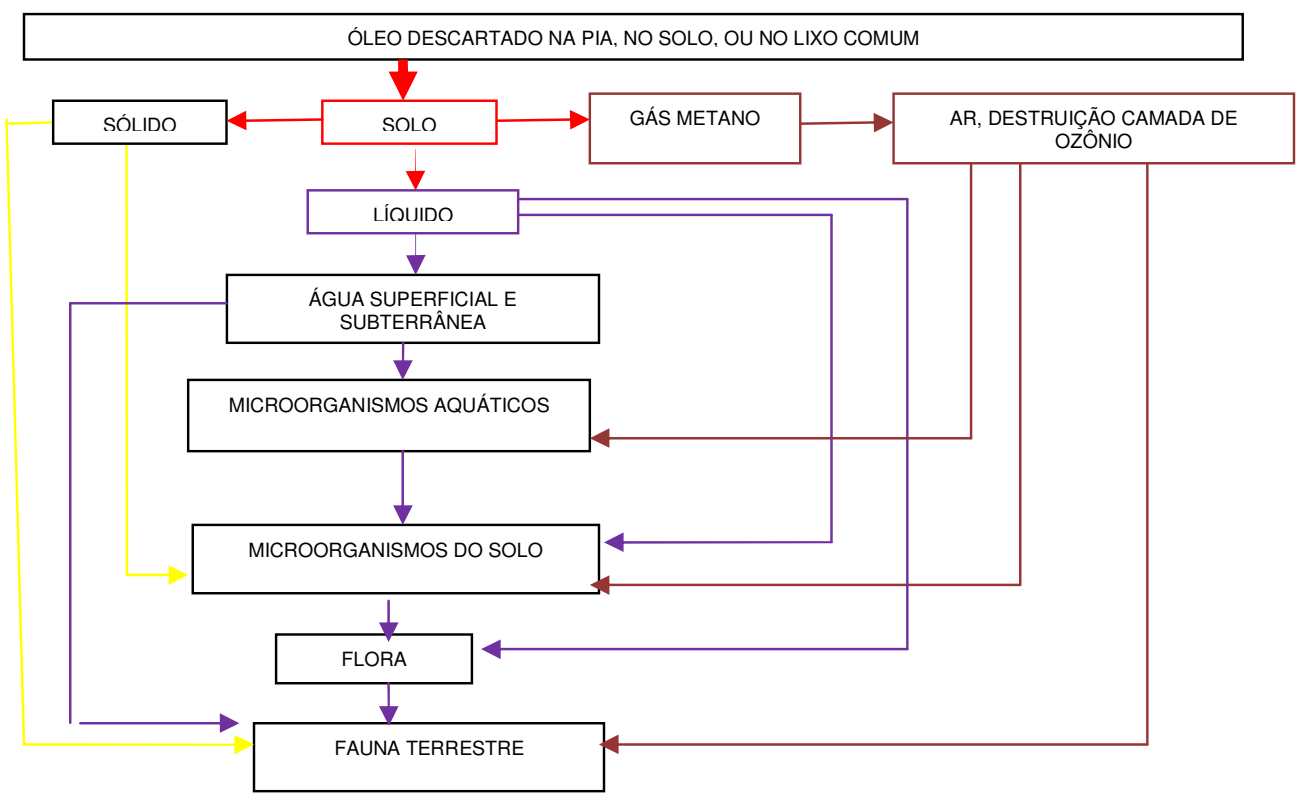

Figura 3 - Poluição provocada pelo óleo no meio ambiente

\section{Doenças que podem ser Provocadas pela Água Contaminada}

Uma vez contaminada a água torna-se veículo transmissor de doenças a água contaminada é responsável por cerca de $80 \%$ das doenças que atingem as pessoas nos países em desenvolvimento, sendo responsável anualmente, segundo o Programa das Nações Unidas para o 


\section{Revista Eletrônica em Gestão, Educação e Tecnologia Ambiental}

REGET/UFSM (e-ISSN: 2236-1170).

Desenvolvimento (PNUD), pela morte de 1,8 milhões de crianças por diarréia (o equivalente a 205 crianças por hora). Além disso, 443 milhões faltam à escola por doenças causadas pelo consumo de água inadequada, metade dos leitos hospitalares é ocupada por doenças causadas pelo uso de água imprópria e metade da população dos países em desenvolvimento passa por algum problema de saúde dessa natureza.

No quadro abaixo são citadas as principais doenças causadas pela água contaminada segundo o Ministério da Saúde.

\begin{tabular}{|c|c|}
\hline Doença & Forma de contágio \\
\hline Meningoencefalite & Pelo contato (consumo ou banho) com águas contaminadas \\
\hline Cólera & Com o consumo de águas contaminadas por fezes ou vômito \\
\hline Leptospirose & Contato com água contaminada por urina de ratos \\
\hline Febre tifóide & Ingestão de águas ou alimentos contaminados \\
\hline Gastrenterites & Ingestão de águas ou alimentos contaminados por fezes \\
\hline Desenteria bacilar & Ingestão de águas contaminadas e sem tratamento \\
\hline
\end{tabular}

Figura 4 - Principais doenças causadas pela água contaminada segundo o Ministério da Saúde Fonte: Elaboração própria a partir do guia de bolso do Ministério da Saúde.

\section{Produtos Derivados do OGR}

Após diversos estudos sobre a viabilidade do OGR em retornar a linha de produção de bens de consumo, no Brasil, parte do óleo vegetal residual oriundo do consumo humano já é destinado a fabricação de sabões (NETO et al., 2000) e, em menor volume, à produção de biodiesel (FERRARI; OLIVEIRA; SCABIO, 2005). Os produtos gerados a partir do uso do OGR, como por exemplo, o bicombustível, também gera subprodutos. O bicombustível é fabricado por meio de um processo químico chamado transesterificação, na qual a glicerina é separada da gordura ou do óleo vegetal, e também gera subprodutos, como os ésteres (o nome químico do biodiesel) e a glicerinaproduto, valorizado no mercado de sabões (PARENTE, 2003).

Estas atitudes trazem o resíduo de volta ao ciclo de vida de consumo sem a interferência de poluição no meio ambiente e refletindo na alternativa econômica nas indústrias que necessitam do material e geram renda. Reis (2007) relata que:

Ao contrário da grande maioria dos resíduos, os óleos exauridos, tanto de origem vegetal quanto animal (gorduras), possui valor econômico positivo, por poderem ser aproveitados em seu potencial mássico e energético. Os principais aproveitamentos de tais óleos são (1) saponificação, com aproveitamento do subproduto da reação, a glicerina, (2) padronização para a composição de tintas (óleos vegetais insaturados - secativos), (3) produção de massa de vidraceiro, (4) produção de farinha básica para ração animal, (5) queima em caldeira, (6) produção de biodiesel, obtendo-se glicerina como subproduto. (REIS, 2007)

O autor relata ainda que o reaproveitamento do resíduo de óleo proveniente de fritura alimentar no ciclo produtivo caracteriza-se como atitude de desenvolvimento sustentável. Ou seja, desfaz a necessidade da extração de recursos naturais e gera o aumentando no incentivo do processo de reciclagem, agregando valores econômicos à cadeia produtiva, socioeconômico e ao mesmo tempo contribuindo para a preservação e conservação dos recursos naturais.

No quadro abaixo são apresentados os benefícios do reaproveitamento do resíduo de óleo. 
Revista Eletrônica em Gestão, Educação e Tecnologia Ambiental

REGET/UFSM (e-ISSN: 2236-1170).

\begin{tabular}{|c|c|}
\hline \multicolumn{2}{|c|}{ Benefícios do reaproveitamento do resíduo de óleo } \\
\hline Econômicos e Sociais & Ambientais \\
\hline $\begin{array}{l}\text { - Assegura renda em áreas carentes, } \\
\text { constituindo fonte permanente de ocupação e } \\
\text { remuneração para mão-de-obra não } \\
\text { qualificada. } \\
\text { - Injeta recursos nas economias locais através } \\
\text { da criação de empregos, recolhimentos de } \\
\text { impostos e desenvolvimento do mercado. }\end{array}$ & $\begin{array}{l}\text { - Favorece o desenvolvimento da consciência ambiental, } \\
\text { promovendo um comportamento responsável em relação ao meio } \\
\text { ambiente, por parte das empresas e dos cidadãos. } \\
\text { - Incentiva a reciclagem de outros materiais. } \\
\text { - Reduz o volume de lixo gerado, contribuindo para a solução da } \\
\text { questão do tratamento de resíduos resultantes do consumo. }\end{array}$ \\
\hline
\end{tabular}

Figura 5 - Benefícios do reaproveitamento do resíduo de óleo.

Fonte: Elaboração própria.

\section{RESULTADOS E DISCUSSÃO}

O presente trabalho estruturou-se em dois momentos. Inicialmente foi apresentada a intenção da pesquisa e aplicado o primeiro questionário. De posse destas informações foi agendada uma palestra com Rosemeri Martins de Oliveira, coordenadora de desenvolvimento sócio ambiental da secretaria do meio ambiente do município de ljuí sobre poluição e contaminação do meio ambiente provocada pelo descarte inadequado do óleo usado. Em seguida foi desenvolvida a oficina de fabricação de sabão a partir do óleo comestível usado e aplicado o segundo questionário que embasou este trabalho.

No primeiro questionário foram aplicadas 11 perguntas, já no segundo foram aplicadas 4 questões. Na questão $n^{\circ} 1$ o grupo alvo da pesquisa, identificou sua função dentro da escola. A partir das respostas obteve-se o perfil do grupo, sendo que este é formado por 32 profissionais, dos quais 14 são professores e correspondem 43,75\%. Já 13 são monitoras, correspondendo a $40,625 \%$ e 5 são funcionarias correspondendo a 15,625\%.

$\mathrm{Na}$ questão $\mathrm{n}^{\circ} 2$ foi solicitado o grau de instrução. Percebeu-se que o grau de instrução varia conforme o cargo e a exigência para admissão. As funcionárias possuem somente o ensino médio, ou seja, um grau acima da escolarização exigida para admissão no cargo (ensino fundamental neste caso). Já $46 \%$ das monitoras possuem ensino médio, $46 \%$ ensino superior, o que demonstra que a maior parte do grupo possui um grau de instrução maior que as funcionárias, mas também possui $7 \%$ do grupo com ensino fundamental que representa o menor grau de instrução de todo o grupo e a escolarização mínima exigida para admissão no cargo. Já em relação aos professores observa-se que $42,86 \%$ do grupo possuem graduação e $42,86 \%$ pósgraduação e apenas 14\% permanece com ensino médio/magistério, escolarização exigida para admissão no cargo.

Na questão $n^{\circ} 3$ o grupo de profissionais caracterizou suas famílias quanto ao numero de pessoas. Também se constatou que o grupo das monitoras possui as famílias maiores, $15,38 \%$ das famílias possuem 5 pessoas e $53,85 \%$ possuem 3 ou 4 pessoas por família. Também possuí as famílias menores, ou seja, $23,07 \%$ com uma ou duas pessoas. Já o grupo das professoras possui $50 \%$ do seu grupo com famílias de 3 pessoas.

$\mathrm{Na}$ questão $n^{\circ} 4$ as profissionais responderam a seguinte pergunta: Quantos litros de óleo sua família consome por mês?

Observa-se nas respostas que um grupo relativamente grande consome até três litros de óleo por mês $53,85 \%$ dos monitores, $35,71 \%$ dos professores e $40 \%$ dos funcionários. Mas 


\section{Revista Eletrônica em Gestão, Educação e Tecnologia Ambiental REGET/UFSM (e-ISSN: 2236-1170).}

observa-se também que o consumo é maior no grupo das famílias maiores, ou seja, 69,23\% das famílias das monitoras possuem 4 ou 5 pessoas e possivelmente compõe o grupo de $53 \%$ que consome entre 2 e 3 litros de óleo mensais. Já o consumo é menor no grupo das professoras, que apesar de possuir $50 \%$ do grupo com 4 pessoas ( 7 famílias), $42,86 \%$ do grupo respondeu que consome entre 1 e 2 litros mensais.

$\mathrm{Na}$ questão $\mathrm{n}^{\circ} 5$ pergunta-se: Quantas vezes em média são feitas frituras em sua residência? Foi possível observar nas respostas que o numero de frituras é maior no grupo dos funcionários, 60\% do grupo faz mais de 5 frituras mensais (as três mencionaram em torno de 15 frituras mensais), e é menor no grupo das monitoras onde $38 \%$ faz somente até 2 frituras mensais. Percebe-se uma relação indireta entre consumo e quantidade de frituras, ou seja, monitoras consomem mais óleo, no entanto fazem menos frituras mensais.

Na questão $n^{\circ} 6$ foi perguntado: Sua família descarta óleo comestível usado?

A partir das respostas conclui-se que o descarte de óleo por família é maior no grupo das funcionárias, onde $60 \%$ descartam mais de $100 \mathrm{ml}$ por mês, mas é menor no grupo das professoras onde $28,58 \%$ descartam entre 50 e $250 \mathrm{ml}$ mensais. Observa-se uma relação direta entre consumo e descarte, ou seja, além de consumir menos óleo mensalmente, o grupo de professores descarta menos.

Na questão $n^{\circ} 8$ perguntou-se: Qual o local utilizado para o descarte do óleo usado na sua residência?

Constatou-se que $30,76 \%$ das monitoras responderam que lança as sobras diretamente no solo ou na pia, enquanto $30,77 \%$ fazem doação e $38,46 \%$ guarda par fazer sabão. Já em relação às professoras, $21,43 \%$ respondeu que lança as sobras diretamente no solo ou na pia, $30,77 \%$ faz doação e $38,46 \%$ guarda par fazer sabão. Já no grupo das funcionárias $20 \%$ faz doação e $20 \%$ guarda par fazer sabão e $20 \%$ descarta no lixo comum. Somando-se os valores descartados na pia, no solo e no lixo comum percebe-se que $25 \%$ do grupo fazem o descarte de forma inadequada causando poluição no meio ambiente.

Na questão $n^{\circ} 9$ questiona-se: Você conhece o destino do óleo que é jogado na pia ou no solo? Cite-o.

Em suas respostas $78,58 \%$ dos professores afirmam que conhecem o destino do óleo que é descartado na pia ou no ralo, enquanto que $100 \%$ dos funcionários desconhecem o mesmo. Mas, apesar de 78,58\% dos professores afirmaram que conhecem o destino do óleo que é descartado na pia ou no ralo, destes apenas $14,29 \%$ citou o solo como prejudicado pela poluição do óleo, $14,29 \%$ citou a água e $21,43 \%$ citou o ar, a água e o solo, o ambiente com um todo com prejudicados, ou seja, apenas $50 \%$ do grupo de professores possuem alguma noção da poluição provocada pelo óleo descartado na pia ou no ralo. Já em relação aos funcionários $46,51 \%$ afirmaram que conhecem o destino do óleo, mas, apenas $23,08 \%$ afirmaram que ele prejudica o solo e 7,1\% citou o ar, a água e o solo, o ambiente com um todo com prejudicados.

Somando-se professores e funcionários observa-se que apenas $12,5 \%$ do total do grupo funcional da escola possuem noção da poluição do ambiente como um todo pelo óleo descartado inadequadamente.

Na questão $n^{\circ} 10$ pergunta-se: Em sua opinião, qual é o descarte mais adequado para o óleo usado?

$80 \%$ dos funcionários, $61,54 \%$ dos monitores e $57,14 \%$ dos professores responderam que o destino mais adequado para o descarte do óleo usado seria a fabricação de sabão perfazendo $62,5 \%$ do total do grupo. Já a coleta seletiva foi citada por $15,38 \%$ dos monitores e $10 \%$ dos funcionários não sendo mencionada pelo grupo de professores perfazendo $9,37 \%$ do total do 


\section{Revista Eletrônica em Gestão, Educação e Tecnologia Ambiental REGET/UFSM (e-ISSN: 2236-1170).}

grupo. O reaproveitamento foi citado por $42,86 \%$ dos monitores, $23,08 \%$ pelo grupo de professores, não sendo mencionada pelo grupo dos funcionários perfazendo $28,13 \%$ do total do grupo. Observa-se que a maior parte do grupo $62,5 \%$ respondeu como melhor alternativa a fabricação de sabão, possivelmente já induzido pela proposta de reciclagem de óleo comestível que estava chegando à escola.

Na questão $n^{\circ} 11$ questiona-se: Você participaria de um programa de coleta seletiva de óleo usado?

A maior adesão foi do grupo de monitoras onde $69,23 \%$ responderam que sim, sendo que a menor adesão foi do grupo de professores, onde apenas $54,14 \%$ aderiram, mas foram justificadas, pois 3 professoras $(21,43 \%)$ que afirmaram que já produzem sabão em suas residências, ou doam para alguém da família que o produz.

De posse de todas estas informações ficou clara a necessidade de um esclarecimento sobre as questões de poluição provocadas no ambiente pelo óleo descartado inadequadamente. Foi então agendada uma palestra com a secretaria do meio ambiente, seguida de uma oficina de fabricação de sabão. No dia seguinte, após ser cotado e embalado, o sabão fabricado foi distribuído ao grupo de profissionais com a respectiva receita. Após estas duas atividades foi aplicado ao segundo questionário no qual foram levantados os seguintes questionamentos:

Questão 1- Em sua opinião qual é o destino do óleo que é jogado na pia ou no solo ou no lixo comum?

Constatou-se que $100 \%$ dos professores e $100 \%$ dos funcionários e $92,31 \%$ dos monitores respondeu que ele contamina todo o ambiente, enquanto somente $7,69 \%$ dos monitores mencionaram que contamina somente o solo. Comparando as respostas da questão $n^{\circ} 9$ onde apenas $12,5 \%$ responderam que ele contamina o ambiente como um todo, observa-se que o grupo obteve uma ótima compreensão do nível de poluição provocada pelo descarte inadequado do óleo comestível usado, chegando após a palestra a $96,88 \%$ do grupo de profissionais.

$\mathrm{Na}$ questão $\mathrm{n}^{\circ} 2$ foi questionado: A partir de hoje, qual o método de descarte que você vai adotar em sua casa?

Comparando as respostas da questão $n^{\circ} 8$ anterior a palestra, com a questões $n^{\circ} 2$, observase que $25 \%$ do grupo fazia o descarte de forma inadequada causando poluição no meio ambiente. Após a palestra $12,5 \%$ optou por doação, $56,25 \%$ fazer sabão e $31,25 \%$ doação para posto de coleta. Observa-se que $100 \%$ do grupo optaram por métodos menos poluentes para o descarte do óleo comestível.

Na questão $n^{\circ} 3$ foi perguntado: Caso sua resposta na questão anterior seja: "Fabricação de sabão," qual a quantidade de óleo a ser utilizada mensalmente?

Percebe-se que a adesão foi maior no grupo de professores onde $25 \%$ do grupo responderam que utilizaria alguma quantidade para fazer sabão. A adesão das monitoras foi de $21,88 \%$ e das funcionarias de $9,38 \%$. A quantidade mencionada foi diretamente proporcional a adesão, ou seja, a maior quantidade foi citada pelos professores, $4850 \mathrm{ml}(38,49 \%)$, seguida pelas monitoras $4500 \mathrm{ml}(35,72 \%)$ e funcionarias $3250 \mathrm{ml}$ (25,79\%). Somando-se os valores, observa-se que uma grande diminuição no impacto ambiental causada pelo descarte inadequado do óleo. Em um mês somente com a opção da fabricação de sabão seriam utilizados $12600 \mathrm{ml}$ de óleo usado. Isto significa que 12 milhões e 600 mil de litros de água deixariam de ser contaminados pelo descarte inadequado do óleo.

Na questão $n^{\circ} 4$ foi perguntado: Caso sua resposta na questão $n^{\circ} 2$ seja: "Doação para posto de coleta," qual a quantidade de óleo a ser doada mensalmente? 
WILDNER \& HILLIG, v(5), $n^{\circ} 5$, p. 813 - 824, 2012.

Revista Eletrônica em Gestão, Educação e Tecnologia Ambiental

REGET/UFSM (e-ISSN: 2236-1170).

Percebe-se que a adesão a doação foi maior no grupo de monitoras onde $18,75 \%$ do grupo responderam que doaria alguma quantidade, a adesão das professoras foi de $15,63 \%$ e das funcionarias de $6,25 \%$. Também é possível constatar que a quantidade doada foi diretamente proporcional a adesão, ou seja, a maior quantidade foi citada pelas monitoras $18,75 \%$, seguida pelas professoras, $15,63 \%$ e funcionárias $6,25 \%$. Somando os valores, observa-se novamente a diminuição no impacto ambiental causada pelo descarte inadequado do óleo. Em um mês somente com a doação para o posto de coleta seriam arrecadados $12750 \mathrm{ml}$ de óleo usado. Isto significa que mais 12 milhões 750 mil de litros de água deixariam de ser contaminados pelo grupo de profissionais em questão.

\section{CONCLUSÃO}

Considerando que a sensibilização e o desenvolvimento de competências são alguns dos objetivos da Educação Ambiental, a prática de fabricação de sabão atingiu seus objetivos na medida em que no primeiro questionário apenas $12,5 \%$ dos entrevistados responderam que o óleo descartado na pia ou no solo polui o ambiente como um todo, ou seja, a água, o ar e o solo. Já no questionário $n^{\circ} 2$ aplicado após a realização da palestra e oficina de fabricação do sabão este numero subiu para $96,88 \%$.

Em relação a propostas de fabricação de sabão, observou-se que $56,26 \%$ do grupo demonstraram interesse e respondeu que adotaria o mesmo. Já a proposta de montar um ponto de coleta na escola recebeu adesão de $40,63 \%$. Neste caso $96,89 \%$ do grupo respondeu que adotaria métodos de descarte que não prejudicariam o meio ambiente.

Juntas as praticas de fabricação de sabão e abertura do posto de coleta na escola, evitariam um descarte mensal inadequado de $25350 \mathrm{~L}$ de óleo usado, ou seja, 25 milhões e 350 mil litros de água deixariam de ser poluídos em um único mês. Em um ano isto significaria 304 milhões e 200 mil litros de água que não seriam poluídos pelo descarte inadequado do óleo comestível usado.

Outro ponto positivo foi o relato de duas profissionais que já fabricaram o sabão e o interesse do grupo em adquirir o sabão para consumo em suas residências. No $1^{\circ}$ mês 13 pessoas adquiriram 9,5 $\mathrm{Kg}$ de sabão na escola e no segundo 9 pessoas adquiriram $8 \mathrm{Kg}$, o que significa que além do óleo não poluir mais o meio ambiente, o sabão já esta substituindo outros produtos químicos de limpeza que possivelmente também poluem o ambiente.

O posto de coleta proposto pela secretaria do meio ambiente para ser montado na escola ainda não entrou em funcionamento por falta das bobonas de armazenamento, mas somente nos dois primeiros meses após a palestra foram recolhidos em recipientes de vidro e de garrafas pet em torno de 12 litros de óleo usado, que foram usados em parte para fabricação de sabão e o restante encaminhado par ACATA (Associação de Catadores de Material Reciclável de ljuí) que utiliza o mesmo para fabricação de sabão.

Além de ter conscientizado o grupo sobre o descarte inadequado do óleo comestível e as conseqüências deste ato para o meio ambiente, a atividade de fabricação de sabão e abertura do posto de coleta como métodos de reciclagem para o óleo comestível foram bem aceitos pelo grupo. Através dos resultados obtidos nos questionários também é possível afirmar que os 32 profissionais que trabalham na escola, estão conscientes dos danos provocados ao meio ambiente pelo descarte inadequado do óleo comestível usado e podem ser além de professoras, monitoras e funcionarias, excelentes multiplicadores ambientais. 


\section{Revista Eletrônica em Gestão, Educação e Tecnologia Ambiental \\ REGET/UFSM (e-ISSN: 2236-1170).}

A partir disso é possível concluir que atividades simples de esclarecimento e conscientização são suficientemente eficientes para conscientizar e mudar as atitudes das pessoas, que muitas vezes adotam métodos de descarte inadequado para os seus resíduos unicamente por falta de informações e conhecimento dos danos que esta atitude pode provocar.

Portanto atividades de esclarecimentos conscientização aliada e novos métodos de reciclagem e reutilização de resíduos, além de preservar e manter os recursos naturais que estão escassos, ainda podem se transformar em fonte de renda par boa parcela da população, além de dar destino adequado a um residou altamente poluidor.

\section{REFERÊNCIAS BIBLIOGRÁFICAS}

ALMEIDA, C. M. Biocombustível: uma análise econômica para a região metropolitana de Salvador. $2002.69 f$. Monografia (Trabalho de Conclusão da Especialização em Ciências Econômicas) - Universidade Estadual de Santa Cruz, Ilhéus, Bahia, 2002.

ALBERICI, R. M.; PONTES, F. F. F. Reciclagem de óleo comestível usado através da fabricação de sabão. 2004. Disponível em: <www.unipinhal.edu.br/ojs/engenhariaambiental/include/getdoc.php?id=39\&article=19\&mode=pdf>. Acesso em: 12 set. 2011.

Biodiselbr.com- noticias. Disponível em: www.biodiselbr.com/noticias/piracicaba-oleo-frituira-vira-biodisel-sabãoraçãoanimal-29-07-07-Acesso em: 08 ago. 2011.

COSTA NETO, P. R. et al. Produção de biocombustível alternativo ao óleo diesel através da transesterificação de óleo de soja usado em frituras. Química Nova, v. 23, n. 4, p. 531-537, 1999. Disponível em: <http://www.scielo.br/pdf/qn/v23n4/2654.pdf>. Acesso em: 08 ago. 2011.

FERRARI, R. A.; OLIVEIRA, V. S.; SCABIO, A. Biodiesel de soja: taxa de conversão em ésteres etílicos, caracterização físico-química e consumo em gerador de energia. Química Nova, 28(1), p. 19-23, 2005.

NETO, P. R. C. et al. Produção de biocombustível alternativo ao óleo diesel através da transesterificação de óleo de soja usado em frituras. Química Nova, 23(4), p. 531-537, 2000.

NOGUEIRA, G. R.; BEBER, J. Proposta de metodologia para o gerenciamento de óleo vegetal residual oriundo de frituras. 2009. Tese de Mestrado em Bioenergia - Universidade Estadual do Centro-Oeste do Paraná, Irati, 2009. Disponível em: <http://www.unicentro.br/graduacao/deamb/semana_estudos/pdf_09/>. Acesso em: 18 ago. 2011.

PROGRAMA DAS NAÇÕES UNIDAS PARA O DESENVOLVIMENTO. Disponível em: <http://www.pnud.org.br/gerapdf.php?id01=1067>. Acesso em: 29 out. 2011.

REIS, M. F. P. et al. Destinação de óleos de fritura. In: 24을 CONGRESSO BRASILEIRO DE ENGENHARIA SANITÁRIA E AMBIENTAL, Belo Horizonte, 5f, 2007. Disponível em: <http://www.ufrgs.br>. Acesso em: set. 2011.

RABELO, R. A.; FERREIRA, O. M. Coleta seletiva de óleo residual de fritura para aproveitamento industrial. Universidade Católica de Goiás - Departamento de Engenharia - Engenharia Ambiental. Disponível em: <2008http://www.ucg.br/ucg/prope/cpgss/ArquivosUpload/36/file/Continua/COLETA\%20SELETIVA\%20DE\%20\%C3\%9 3LEO\%20RESIDUAL\%20DE\%20FRITURA\%20PARA\%20AP\%E2\%80\%A6.pdf>. Acesso em: 18 set. 2011.

SAMPAIO, L. A. G. Reaproveitamento de óleos e gorduras residuais de frituras: tratamento, matéria-prima para produção de biodiesel. 2003. 59f. Dissertação (Mestrado em Desenvolvimento Regional e Meio Ambiente) Universidade Estadual de Santa Cruz, Ilhéus, 2003. 